\title{
Pembinaan Akhlak Melalui Dharma Pramuka: Studi Fenomenologi di Madrasah Aliyah Negeri
}

\author{
Maryanis \\ Program Pascasarjana Universitas Muhammadiyah Sumatera Barat \\ maryanis.spdi@gmail.com
}

\begin{abstract}
This research aims to explain the material, methods and evaluation system in moral coaching through dharma Pramuka in MAN Pariaman City. Research uses qualitative methods with this type of phenomenological research. The results in this study show that the material in moral coaching through the Scout dharma in MAN Pariaman City is contained in the scout honor code that is takwa to the One True God; the love of nature and the compassion of fellow human beings are willing in helping anyone and patiently do for good. Methods in moral coaching through dharma Pramuka in MAN Pariaman City there are exemplary methods, habituation and lecture methods, and evaluation system in moral coaching through dharma scouting in MAN Pariaman City is carried out through muhasabah, devotion al-all activities with evening wirid events.
\end{abstract}

Keywords: Scouting; moral development; Materials and Method

\begin{abstract}
Abstrak
Penelitian ini bertujuan menjelaskan materi, metode dan sistem evaluasi dalam pembinaan akhlak melalui dharma Pramuka di MAN Kota Pariaman. Penelitian menggunakan metode kualitatif dengan jenis penelitian fenomenologi. Hasil pada penelitian ini menunjukkan bahwa materi dalam pembinaan akhlak melalui dharma Pramuka di MAN Kota Pariaman terdapat dalam kode kehormatan pramuka yaitu takwa kepada Tuhan Yang Maha Esa; cinta alam dan kasih sayang sesama manusia rela dalam menolong siapapun dan sabar berbuat untuk kebaikan. Metode dalam pembinaan akhlak melalui dharma Pramuka di MAN Kota Pariaman ada metode teladan, pembiasaan dan metode ceramah, dan sistem evaluasi dalam pembinaan akhlak melalui dharma pramuka di MAN Kota Pariaman dilakukan dengan melalui muhasabah, kegiatan kemah bakti dengan acara wirid malam.
\end{abstract}

Kata Kunci: Pramuka; Pembinaan Akhlak; Mareri dan Metode 


\section{Pendahuluan}

Akhlak secara terminologi berarti tingkah laku seseorang yang didorong oleh suatu keinginan secara sadar untuk melakukan suatu perbuatan yang baik ${ }^{1}$. Akhlak merupakan bentuk jamak dari kata khuluk, berasal dari bahasa Arab yang berarti perangai, tingkah laku atau tabiat ${ }^{2}$. Akidah akhlak merupakan tiga pondasi yang mendasar dari perintah Agama. Islam memiliki Aqidah, menjalankan Syariah Islam serta memiliki akhlak yang mulia, dari tiga pondasi akhlak di atas dapat dipahami bahwa saling keterkaitan antara satu dengan yang lainnya. Akhlak disebut dengan etika sehingga dapat menggambarkan arah suatu tujuan yang hendak dicapai agama Islam sehingga hasil dari sesuatu merupakan sebuah usaha yang diterapkan akidah dan syari'ah ${ }^{3}$.

Akhlak yang baik adalah ibarat pondasi dasar bangunan yang kokoh ${ }^{4}$. Maka manusia akan berakhlak yang baik jika memiliki secara akidah serta syari'ah dengan benar ${ }^{5}$. Oleh sebab itu, ketiga komponen tersebut harus saling berkaitan dan saling melengkapi dalam individu setiap makhluk hidup terutama bagi umat muslim, seperti contoh pada sebuah pohon dan akarnya itu adalah gambaran dari sebuah akidah, sementara batang, dahan dan daunnya pohon bisa digambarkan sebagai lambang syariat, sedangkan buah dari pohon yang dimaksud bisa dilambangkan sebagai akhlak.

Secara bahasa akhlak dapat diartikan budi pekerti yang dimiliki manusia, tingkah laku atau kebiasaan sehari-hari yang sudah menjadi pakaianya dalam kehidupannya. Pada dasarnya manusia lahir ke dunia telah mempunyai genggaman yang baik terutama akhlak yang baik, akan tetapi ada beberapa factor yang mengakibatkan akhlak manusia baik atau tidaknya yaitu karena factor didikan orang tua, lingkungan dan sekolah ${ }^{6}$. Jika ketiga factor ini mendukung dengan baik maka baiklah akhlaknya apabila ketiga factor tidak mendukung dengan baik maka tidak baik akhlaknya.

${ }^{1}$ Muhammad Yusuf, Mahyudin Ritonga, and Mursal, "Implementasi Karakter Disiplin Dalam Kurikulum 2013 Pada Bidang Studi PAI Di SMA Islam Terpadu Darul Hikmah,” Jumal Tarbiyatuna 11, no. 1 (2020):

49-60, https://doi.org/https://doi.org/10.31603/tarbiyatuna.v11i1.3437 Article.

${ }^{2}$ Mahyudin Ritonga, "Bargaining Kata Di Dalam Al Qur'an : Kontroversi Ahli Terhadap Bahasa Al Qur'an," Akademika 21, no. 2 (2016): 229-54, http://ejournal.metrouniv.ac.id/index.php/akademika/article/view/466.

${ }^{3}$ Anas Elmelki and Ben Arab Mounira, "Ethical Investment and the Social Responsibilities of the Islamic Banks," International Business Research 2, no. 2 (2019): 123-30, https://doi.org/10.5539/ibr.v2n2p123.

${ }^{4}$ Rohmad Qomari, "Prinsip Dan Ruang Lingkup Pendidikan Aqidah Akhlaq," INS ANLA: Jurnal Pemikiran Alternatif Kependidikan 14, no. 1 (2009): 1-16.

5 Khaled Abou El Fadl, "Qur'anic Ethics and Islamic Law," Journal of Islamic Ethics 1 (2017): 7-28, https://doi.org/10.1163/24685542-12340002.

6 Ahmad Ichsan Yafi Hutagalung, Humaidah Hasibuan, and Yusnaili Budianti, "Peran Guru Dalam Menanamkan Akhlak Di Kelompok B RA As-Sa'adah Kecamatan Medan Area," Raudhab 06, no. 01 (2018): 1-9, http://jurnaltarbiyah.uinsu.ac.id/index.php/raudhah. 
Pada dasarnya peserta didik tidak menginginkan keburukan yang terjadi pada dirinya apalagi tidak memiliki akhlak seperti yang diajarkan Rasullullah SAW. Oleh karena itu maka perlu pembinaan akhlak dalam kehidupan umat manusia, salah satunya dengan melalui pembinaan akhlak yang diberikan secara terus menerus yaitu pembinaan akhlak melalui keluarga, pembinaan akhlak melalui masyarakat dan pembinaan akhlak melalui pendidikan di sekolah ${ }^{7}$. Pembinaan Akhlak tersebut perlu dilakukan semenjak dini pada setiap jenjang pendidikan yang menadi suatu kebutuhan utama dalam diri peserta $\operatorname{didik}^{8}-$ ?

Menurut informan yang merupakan Pramuka ambalan di MAN Kota Pariaman, yang menjelaskan tentang paramuka ambalan yang aktif sudah dikatakan baik akhlaknya karena mereka sudah menepati Dharma Pramuka khususnya ketika mereka dilantik pramuka dewan ambalan, contohnya ketika dalam latihan pramuka berkumadangnya azan maka semua kegiatan dihentikan agar seluruh angota pramuka melaksanakan sholat berjamaah, diawal bulan anggota pramuka ambalan selalu melaksanakan makan bersama untuk kebersamaan sesuai dengan Dharam yang ke dua. Sementara bagi anggota pramuka ambalan yang kurang aktif dalam mengikuti latihan dan kegiatan pramuka maka memang terlihat akhlaknya kurang baik, merka masih ada yang cabut, merokok dan bahkan tinggal kelas karena tidak mencerminkan sikap yang baik di sekolah sebagai anggota pramuka ambalan di MAN Kota Pariaman.

Berdasarkan Program yang sudah dilaksanakan sekolah MAN Kota Pariaman sesuai hasil penilaian Pembina dan pelatih bahwa sudah ada anggota pramuka yang sudah mengamalkan Dasa Darma pramuka yang bisa membina akhlak siswa dalam 3 ranah yaitu: bagaimana hubungan atau Akhlak terhadap Allah, bagaimanan hubungan atau Akhlak terhadap Manusia dan bagaimana hubungan atau Akhlak terhadap Masyarakat dan juga masih ada anggota pramuka yang masih kurang mengamalkan Dasa Darma Pramuka dan belum mencerminkan berakhlak yang baik terhadap Allah, berakhlak yang baik terhadap manusia dan berakhlak yang baik terhadap masyarakat.

\section{Metodologi Penelitian}

Metode Penelitian ini adalah metode kualitatif. Maksudnya adalah penulis mengunakan metode kualitatif dengan jenis penelitian yang penulis pakai adalah

${ }^{7}$ Rosniati Hakim and Mahyudin Ritonga, "A Study of Religion Education Method With Multicultural Insight," in International Seminar on Islamic Education (ISIE 2018) Faculty of Islamic Religion, Universitas Mubammadiyah Ponorogo, July 07th, 2018 (Ponorogo: Universitas Muhammadiyah Ponorogo, 2018), 81-97.

${ }^{8}$ Gillian M Boulton-lewis et al., "Moral and Social Development: Teachers' Knowledge of Children's Learning and Teaching Strategies in the Early Years," Australasian Journal OfEarly Childhood, no. July 2015 (2011): 1-20.

${ }^{9}$ Rosniati Hakim et al., "Implementation of Contextual Teaching and Learning in Islamic Education at Madrasah Diniyah," Journal of Advanced Research in Dynamical \& Control Systems 12, no. 02 (2020): 3326-32, https://doi.org/10.5373/JARDCS/V12I2/S20201455. 
pendekatan fenomenologi Menurut Hasbian pendekatan fenomenologi adalah sebagai salah satu bentuk penelitian kualitatif yang tumbuh dan berkembang dalam bidang sosial dan pendekatan fenomenologi ini yang menjadi pokok kajian fenomena yang tampak sebagai subjek penelitian peneliti ${ }^{10}$.

Penggunaan pendekatan fenomenologi adalah untuk mengetahui Kondisi tingkah laku peserta didik Ambalan dalam kehidupan keseharian mereka. Adapun data yang penulis dapatkan terkait dengan objek penelitian Penulis dari MAN Kota Pariaman adalah Jumlah Peserta didik yang masuk ekstrakurikuler pramuka yang di sebut dengan Pramuka Ambalan berjumlah 356 Orang yang terdiri dari pramuka ambalan yang aktif dan pramuka ambalan yang kurang aktif, 1 Orang Kamabigus, 1 Orang Pembina pramuka, 1 Orang Pelatih Pramuka yang ada di MAN Kota Pariaman. Sumber data ada dua yaitu data primer, data ini merupakan data pokok dalam sebuah penelitiandan data sekunder yaitu data yang merupakan data penunjang dalam sebuah penelitian.

Prosedur Analisis data yang peneliti lakukan melalui proses menganalisis dan menyusun data secara sistematis yang diperoleh dari observasi, wawancara, catatan lapangan, dan dokumentasi dengan cara mengorganisasikan data kedalam unit-unit, melakukan sintesa, menyusun kedalam pola, memilih mana yang penting dan yang akan dipelajari, dan membuat kesimpulan sehingga mudah dipelajari oleh orang lain.

Dari keterangan yang dijabarkan di atas, maka langkah-langkah yang peneliti tempuh setelah melakukan observasi dan wawancara adalah melakukan teknis analisis data. Dimana data yang diperoleh melalui observasi dan wawancara akan peneliti analisis berdasarkan langkah-langkah di atas yakni dengan memilih datadata yang dibutuhkan dan kemudian dikelompokkan berdasarkan tema-tema yang sesuai dengan permasalahan yang diteliti. Setelah itu, peneliti akan menyajikannya dalam bentuk kata-kata yang bersifat narasi sehingga lebih memudahkan dalam melakukan penarikan kesimpulan.

\section{Hasil dan Pembahasan \\ Materi Pembinaan Akhlak Melalui Dharma Pramuka di MAN Kota Pariaman}

Dalam kegiatan Pramuka banyak kegiatan positif yang bisa diambil, baik untuk diri peserta didik, untuk keluarga maupun lingkungan. Hal ini karena dalam kegiatan Pramuka tidak terlepas dari pembinaan akhlak yang dilakukan. Dalam kegiatan Kperamukaan banyak aturan yang diberikan yang sesuai dengan aturan yang berlaku dalam Kepramukaan. Ini semua bertujuan untuk menghasilkan dan mencetak perilaku atau akhlak peserta didik seperti yang diharapan.

${ }^{10}$ O Hasbiansyah, "Pendekatan Fenomenologi: Pengantar Praktik Penelitian Dalam Ilmu Sosial Dan Komunikasi," MEDLATOR 9, no. 1 (2008): 163-80. 
Setelah peneliti melakukan observasi dan penelitian pada saat latihan rutin di MAN Kota Pariaman, maka sesuai dengan kode kehormatan Pramuka dalam bentuk ketentuan moral (Dasa Dharma Pramuka) maka peneliti akan menjelaskan sebagai berikut:

\section{Dharma Takwakepada Tuhan Yang Maha Esa}

Artinya sebagai anggota Pramuka ambalan meningkatkan keimanan dan ketakwaannya terhadap Allah SW'T sehingga menjadi contoh teladan bagi peserta didik. Beribadah menurut agama dan kepercayaan kepada Tuhan Yang Maha Esa, dengan menjalanakan perintah dan menjauhi laranganNya merupakan tugas manusia sebagai makhluk Allah SW'T.

2. Dharma Cinta alam dan kasih sayang sesama manusia

Artinya, sebagai anggota Pramuka harus mempunyai rasa cinta dan kasih sayang. Baik kepada sesama manusia, lingkungan dan alam sekitar. Saling menyayangi, saling berbagi, saling mengerti. Apabila ada saudara kita merasa susah seharusnya kita dapat merasakan apa yang menjadi kesusahan bagi mereka dengan cara menolong dan membantunya. Begitupun dnegan alam sekitar kita harus bisa menjaga alam ciptaan Allah SWT.

3. Patriot yang sopan dan ksatria

Artinya, anggota Pramuka harus mempunyai jiwa yang patriotik atau pemuda yang cinta tanah air. Mempunyai sikap yang sopan dan siap siaga dalam membela tanah airnya.

4. Patuh dan suka bermusyawarah

Artinya, anggota Pramuka harus patuh terhadap aturan yang telah ditetapkan oleh pemimpin Pramuka. Suka bermasyarakat dan selalu bermusyawarah dalam melakukan atau mengambil suatu tindakan. Pramuka adalah seorang pribadi yang setia dan teguh dalam memegang prinsip, baik prinsip terhadap diri sendiri ataupun prinsip yan telah ditentukan suatu organisasi.

5. Rela menolong dan tabah

Artinya, rela menolong adalah sifat yang yang harus dimiliki oleh semua nggota Pramuka. Selalu bersedia dan siap untuk melakukan perbuatan baik kepada sesama, baik sesama manusia, lingkungan maupun kepada hewan atau tumbuhan. Dengan adanya sifat tolong menolong maka beban anggota orang yang ditolong akan merasa terbantu sehingga dapat menyelesaikan tujuan atau tugas tersebut.

6. Dharma Rajin, terampil dan gembira

Rajin atau tekun dalam aspek Dasa Darma kegiatan Pramuka adalah rajin dan tekun dalam segala kegiatan yang positif. Rajin bukan hanya dalam 
kegiatan yang dilakukan dalam lingkup kepramukaan saja tetapi rajin dan tekun dalam segala hal baik bagi diri sendiri, ditengah keluarga dan dilingkungan masyakarat.

7. Dharma Hemat, cermat dan bersahaja

Dalam penerapan dasadharma Pramuka yang ke tujuh di MAN Kota Pariaman dapat dilihat dari kegiatan anggota Pramuka MAN Kota Pariaman yang menerapkannya dalam bentuk menabung.

8. Dharma Disiplin, berani dan setia

Salah satu sifat anggota Pramuka yang harus diterapkan dan tidak boleh dilanggar adalah disiplin yang dibarengi dengan berani dan setia. Kata disiplin berasal dari bahasa Latin "discipulus" yang berarti "pembelajaran"." implementasi sifat disiplin berani dan setia di MAN Kota Pariaman dapat terlihat dari keseharian peserta didik yang teratur dalam melaksanakan kegiatan. Disiplin dalam berpakaian dan disiplin dalam kegiatan latihan. Anggota Pramuka di MAN Kota Pariaman juga berani dalam mengambil keputusan dan berani untuk mempertanggungjawabkan keputusan tersebut.

9. Dharma Bertanggungjawab dan dapat dipercaya

Implementasi dalam dasadharma bertanggung jawab dan dapat dipercaya ini dapat dilihat pada saat kegiatan Pramuka berjalan di MAN Kota Pariaman bahwa setiap anggota Pramuka dapat menjalanakan wewenang yang telah diberikan kepada mereka. Ini mereka lakukan tanpa paksaan dan kesadaran sendiri.

10. Dharma Suci dalam pikiran, perkataan dan perbuatan

Artinya, anggota Pramuka harus mempunyai pemikiran yang jernih, suci baik itu dalam perkataan dan perbuatnnya. Dharma pramuka yang terakhir akan dapat terwujud apabila sembilan dharma sebelumnya sudah terlaksana dengan sempurna ${ }^{12}$. Dengan adanya dharma suci dalam pikiran perkatan dan perbuatan ini maka salah satu tujuan pendidikan Pramuka adalah menciptakan dan mewujudkan akhlak yang mulia yang dapat diaplikasikan dalam kehidupan sehari-hari ${ }^{13}$. Dharma ini aplikasi dan implikasi penerapannya adalah satu bentuk amal jariyah yang tidak akan terlepasa dari lingkungan agama, lingkungan budaya serta lingkungan adat istiadat lainnya.

Banyak hal yang bisa diberikan untuk peserta didik dalam pembinaan akhlak khususnya di MAN Kota Pariaman. Dalam hal ini materi pembinaan akhlak melalui Dharma Pramuka di MAN Kota Pariaman diterapkan melalui dua kode

11 Ariesandi, Rahasia Mendidik. Anak. Agar Sukses dan Babagia, Tips dan Terpuji Melejitkan Potensi Optimal Anak, (Jakarta: PT Gramedia Pustaka Utama, 2008), blm. 230-231.

${ }^{12}$ Sarah Mills, "Scouting for Girls? Gender and the Scout Movement in Britain," Gender, Place \& Culture 18, no. 4 (2011): 537-56, https://doi.org/10.1080/0966369X.2011.583342.

${ }^{13}$ Haidir, Daisy JP, and Evi Idayani, "Implementation of Moral Values in Scouts (Study on Madrasah Ibtidaiyah State 1 Medan)," Budapest International Research and Critics Institute-Journal (BIRCIJournal) 3, no. 2 (2020): 1403-12, https://doi.org/https://doi.org/10.33258/birci.v3i2.1000. 
kehormatan Pramuka yaitu (1) Takwa Kepada Tuhan Yang Maha Esa dan (2) Cinta Alam dan Kasih Sayang Sesama Manusia. Materi pembinaan akhlak terhadap tuhan Yang Maha Esa yang diberikan oleh pembina, pelatih dan kamabigus di MAN Kota Pariaman diterapkan melalui kegiatan ibadah. Para peserta didik diajak langsung untuk mengadakan kegiatan shalat berjamaah, mengadakan tadarusan ketika latihan akan dimulai dan melaksanakan puasa Senin Kamis. Kegiatan ini juga langsung diikuti oleh pelatih dan pembina secara langsung, sehingga dalam kegiatan ini antara pelatih, pembina dan peserta didik tidak ada batasan. Melalui program ini, diharapkan adanya kesadaran peserta didik untuk melaksanakan kegiatan ibadah tanpa ada paksaan baik itu ditengah keluarga, dilingkungan sekolah dan lingkungan masyarakat sekitar.

Pada kegiatan lainnya peserta didik melakukan kegiatan bakti sosial yang lamngsung didampingi oleh pembina dan pelatih. Pembinaan ini dilakukan baik secara langsung maupun secara tidak langsung, seperti pelatih ikut serta ketika memberikan bantuan kepada fakir miskin yang ada disekitar. Membagikan ta'jil pada bulan Ramadahan dan ikut serta dalam kegiatan operasi semut terhadap lingkungan sekolah, mesjid dan masyarakat. Berdasarkan temuan data yang telah peneliti uraikan diatas yang terkait dengan fokus penelitian, maka dapat ditemukan materi pembinaan akhlak terhadap Dharma Pramuka di MAN Padusunan Kota Pariaman pada Tahun Pelajaran 2020/2021 dapat dilihat sebagai berikut:

Pertama, Menerapkan Dasa Darma pertama dengan materi pembinaan akhlak terhadap Allah SWT yang diterapkan oleh Pramuka di MAN Kota Pariaman adalah melalui pembiasaaan dalam beribadah. Hal ini dapat terlihat dengan terlaksananya kebiasaaan shalat berjamaah, tadarusan sebelum melaksanakan latihan dan melakukan puasa Senin Kamis. Selanjutnya pelatih dan pembina ikut serta dalam melaksanakan program kegaiatan yang disebutkan diatas. Kedua, Menerapkan Dasa Darma ke dua dengan materi pembinaan akhlak terhadap sesama manusia. Hal ini dapat terlihat pembinaan melalui santunan kepada fakir miskin. Seperti pemberian takjil di bulan Ramadhan, bakti sosial dalam lingkungan masyarakat.

Ketiga, Pelatih, pembina dan peserta didik melakukan pembinaan dengan mencintai lingkungan sekitar. Hal ini dapat dilakukan dalam kegiatan bakti sosial dan operasi semut. Dengan adanya kegiatan ini maka akhlak terhadap lingkungan sekitar terjaga dan ada rasa memiliki terhadap alam benda. Keempat, Dalam memberikan materi pembinaan akhlak melalui dharma Pramuka di MAN Kota Pariaman dilakukan oleh pembina, pelatih, guru mata pelajaran Aqidah Akhlak, dan Ustad dalam memberikan ceramah dengan tema pembinaan akhlak anak didik Pramuka.

Temuan ini sejalan dengan pernyataan para penelitian yang mengungkapkan bahwa beberapa nilai-nilai akhlak terdapat dalam dharma pramuka ${ }^{14}{ }_{-}^{15}{ }_{-}$, keberadaan

14 Mislia, Alimuddin Mahmud, and Darman Manda, "The Implementation of Character Education through Scout Activities," International Education Studies 9, no. 6 (2016): 130-38, https://doi.org/10.5539/ies.v9n6p130. 
nillai akhlak dalam Dharma pramuka membuka peluang bagi pendidik untuk melakukan pembinaan akhlak terhadap peserta didik melalui dharma pramuka. ${ }^{16}$

Materi pembinaan akhlak melalui Dharma Pramuka di MAN Kota Pariaman dapat dilakukan dalam proses belajar mengajar (kelas), dalam program latihan (lapangan dan Hall) dan di dalam program pemberian cermah (Mushalla atau Masjid). Biasanya materi diberikan ketika jadwal pelajaran Aqidah Akhlak, kegiatan ekstrakurikuller dan ketika program Tablig Akbar sekali dalam 2 bulan.

\section{Metode Pembinaan Akhlak Melalui Dharma Pramuka di MAN Kota Pariaman}

Metode berarti cara dalam melakukan kegiatan atau sesuatu. Dalam organisasi kepramukaan metode pembinaan akhlak melalui Dharma Pramuka khususnya di MAN Padusunan Kota Pariaman ada beberapa metode yang diterapkan walau belum maksimal seperti metode pramuka satuan terpisah antara putra dan putri.

1. Ceramah.

Metode atau cara ceramah atau cara pembinaan melalui ceramah adalah metode yang dilakukan oleh pelatih dan pembina dengan cara memberikan ceramah kepada adik-adik anggota Pramuka. Metode ini maksudnya memberikan penjelasan tentang kebenaran dan kemaslahatan kepada adik-adik anggota Pramuka. Tujuan metode ceramah ini adalah untuk memberikan nasehat baik itu secara langsung maupun tidak langsung. Secara langsung bisa dilihat dari cara pelatih dan pembina memberikan nasehat melalui ceramah tentang hal-hal yang baik, sedangkan secara tidak langsung dengan cara memberikan nasehat melalui ceramah dengan bercerita.

2. Teladan.

Metode pembinaan akhlak kepada peserta didik dengan melalui keteladanan maksudnya memberikan contoh secara langsung atau nyata kepada peserta didik atau anggota Pramuka di MAN Padusunan Kota Pariaman. Keteladan ini baik dari segi ibadah, belajar mengajar ataupun dalam kegiatan sehari-hari. Keteladanan ini biasanya diajarkan langsung oleh pembina atau pelatih Pramuka MAN Padusunan Kota Pariaman.

Keberadaan metode menurut Ritonga adalah salah satu kunci utama dalam melakukan setiap aktivitas ${ }^{17}$, pernyataan yang tidak jauh berbeda juga diungkapkan oleh Aprianto dan kawan-kawan yang menegaskan bahwa metode selain

15 Ahmad Muhtadi, "Implementation Of National Character Education (Study Of Scouting Activities Analysis At Man 2 Karanganyar)," Attarbiyab: Journal of Islamic Culture and Education 4, no. 1 (2019): 41-68, https://doi.org/10.18326/attarbiyah.v4i1.41-68.

16 Muhammad, "Pembentukan Karakter Anak SD/MI Melalui Pendidikan Pramuka," Elementary 1, no. 2 (2015): 10-17.

${ }^{17}$ Mahyudin Ritonga, "Desain Bahan Ajar Bahasa Arab Sains Dengan Pendekatan Whole Language," Eduksi: Jurnal Pendidikan Islam 5, no. 1 (2017): 1-24. 
mempercepat tercapainya tujuan juga memaksimalkan hasil yang diinginkan ${ }^{18}$. Ada beberapa metode yang diterapkan oleh pelatih dan pembina di MAN Kota Pariaman dalam melakukan pembinaan akhlak melalui Dharma Pramuka, salah satunya adalah melalui metode ceramah dan teladan. Dalam memberikan pembinaan akhlak, pelatih dan pembina tidak jarang memberikan nasehat yang berguna untuk kebaikan bagi peserta didik. Ceramah ini biasanya berisi nasehat yang disampaikan secara langsung maupun tidak langsung. Ketika ada peserta didik melakukan tindakan yang salah, maka pelatih dan pembina berhak memberikan nasehat kepada mereka supaya mereka mengubah cara dan tindakan yang salah tersebut. Terkadang pembina dan pelatih memberikan nasehat hanya berupa sebuah teguran tapi tidak jarang juga berupa nasehat yang disampaikan dalam bentuk cerita.

Disamping itu, pelatih dan pembinan tidak segan-segan turun langsung kelapangan untuk memberikan pembinaan akhlak dengan memberikan contoh atau teladan. Seperti ketika mengajak peserta didik untuk menjaga waktu sholat, ketika azan berkumandang maka pelatih dan pembina akan bersegera kemesjid atau mushalla untuk melakukan shalat berjamaah. Maka, dengan itu para peserta didik juga akan mengikuti pelatih dan pembina. Ketika melihat sampah atau kotoran yang ada disekitar lingkungan, pelatih dan pembina tidak sega-segan untuk memungut sampah danmmebuang pada tempatnya. Dengan hal ini maka peserta didik akan meniru atau meneladani sikap yang dicerminkan oleh pelatih dan pembina mereka, sehingga tercapailah pembinaan akhlak yang diinginkan.

Berdasarkan temuan data yang telah peneliti uraikan diatas yang terkait dengan fokus penelitian, maka dapat ditemukan metode pembinaan akhlak terhadap Dharma Pramuka di MAN Padusunan Kota Pariaman pada Tahun Pelajaran 2020/2021 dapat dilihat sebagai berikut:

Pertama, Dalam pembinaan akhlak melalui Dharma Pramuka di MAN Padusunan Kota Pariaman ada dua metode yang dipakai yaitu metode cermah dan melalui teladan. Kedua, Metode ceramah dan teladan diberikan kepada peserta didik di lapangan dan Hall ketika kegiatan latihan berlangsung. Ketiga, Pelatih, pembina dan kamabigus ikut serta memberikan teladan dalam metode pembinaan akhlak melalui dharma Pramuka di MAN Padusunan Kota Pariaman. Keempat, Pelatih, pembina dan guru memberikan nasehat melalui ceramah demi kebaikan anggota Pramuka. Ceramah diberikan baik secara langsung maupun secara tidak langsung. Kelima, Metode pembinaan akhlak dengan mmeberikan teladan bisa diterapkan langsung oleh pembina, pelatih dan kamabigus. Seperti dalam pembinaan akhlak kepada Allah SWT pembina menjaga jadwal ibadah shalat berjamaahnya, melakukan puasa Senin Kamis sehingga peserta didik ikut juga melakukan hal yang

18 Aprianto Aprianto et al., "The Influence of Using Audio- Lingual Method on Students' Speaking Skill in Madrasah Diniyah Takmiliyah Awwaliyyah," Izdihar: Journal of Arabic Language Teaching, Linguistics, and Literature 3, no. 2 (2020): 147-60, https://doi.org/https://doi.org/10.22219/jiz.v3i2.12514. 
sama. Pembina, pelatih dan anggota Pramuka secara bersama-sama juga melakukan bakti sosial, sehingga tercipta upaya pembinaan akhlak terhadap lingkungan sekitar.

Kemampuan pelatih, pembina dan kamabigus dalam memberikan metode pembinaan akhlak kepada peserta didik di MAN Kota Pariaman sangat mempengaruhi terhadap hasil yang diinginkan. Metode yang dipakai berfungsi untuk menggali dan mengaktualkan potensi-potensi positif dalam diri peserta didik.

Sistem Evaluasi dalam Pembinaan Akhlak Melalui Dharma Pramuka di MAN Padusunan Kota Pariaman

Setelah materi pembinaan akhlak dan metode pembinaan akhlak melalui Dharma Pramuka di MAN Padusunan Kota Pariaman, selanjutnya ada sistem evaluasi yang dilakukan dalam pembinaan akhlak melalui Dharma Pramuka. Sistem evaluasi memiliki pengertian bahwa ini adalah merupakan suatu sistem yang tersusun dengan rapi yang bertujuan untuk menilai sumber daya dalam suatu organisasi (Pramuka) dan untuk mendapatkan hasil yang bagus untuk dijadikan tolak ukur tertentu mengenai kinerja sumber daya yang dimaksud diatas. Dalam hal ini organisasi yang dimaksud adalah organisasi Pramuka di MAN Padusunan Kota Pariaman Tahun Pelajaran 2020/2021.

Menurut uraian yang diberikan oleh pembina PA yang diwakili oleh Muslim yang mengatakan mengatakan bahwa, "ada dua sistem evaluasi yang kami terapkan dalam pembinaan akhlak kepada peserta didik di MAN Padusunan Kota Pariaman. Baik itu pembinaan akhlak kepada Allah, pembinaan akhlak kepada manusia maupun pembinaan akhlak terhadap lingkungan. Kami dalam mengevaluasi melaksanakan Perjusmi dengan melakukan jurit malam dan melaksanakan muhasabah. Biasanya kami sebagai pembina dan pelatih akan melakukan di lapangan atau hall dan posko yang telah dibentuk untuk jurit malam.

Senada dengan uraian yang telah dijelaskan oleh Pembina yang diwakili oleh Bapak Muslim diatas, maka Ernawati juga menjelaskan bahwa, "kami melaksanakan evaluasi pembinaan akhlak melalui Dharma Pramuka di MAN Padusunan Kota Pariaman pada malam Jumat disetiap posko yang telah ditentukan, dan pada saat penutupan jurit malam oleh kamabigus. Hal ini sengaja dilakukan pada malam hari karena ini akan menjadi berkesan dan akan selalu teringat oleh mereka peserta didik. Apalagi jurit malam dilakukan pada malam Jumat, maka akan terasa momen yang sangat berkesan antara serius, takut dan keberanian.

Dalam mengevaluasi suatu kegaiatan ada beberapa sistem yang dipakai untuk dijadikan tolak ukur atau perbandingan. Dalam kegiatan Pramuka MAN Kota Pariaman, Perjusami merupakan salah satu sistem yang dipakai dalam mengevaluasi kegiatan pembinaan akhlak melalui Darma Pramuka di MAN Kota Pariaman. Perjusmi dilakukan dengan kegiatan jurit malam, ini bertujuan melakukan pembinaan dengan kegiatan gotong royong. Kegiatan ini dilakukan pada malam hari dan dilakukan di posko-posko yang telah ditentukan. Selanjutnya dengan mengadakan muhasabah diri. Biasanya muhasabah dipimpin oleh seorang ustad atau ahli agama, dengan menafakuri segala perbuatan yang telah dilakukan peserta didik diajak untuk bermuhasabah bersama. Tidak sedikit peserta didik 
menitikan air mata disaat dilakukan muhasabah, mereka merenung, mengingat kembali perjalanan mereka. Dengan adanya kegiatan ini terlihat adanya perubahan karakter pada diri peserta didik. Mereka lebih rajin dalam melakukan shalat berjamaah, rutin melakukan puasa Senin Kamis dan tadarusan jatrang ditinggalkan.

Begitu pula dengan kegiatan alam dan lingkungan sekitar, peserta didik lebih merasa peduli terhadap lingkungan dan memiliki rasa peduli yang tinggi terhadap sesamanya. Berdasarkan pada uraian yang telah disampaikan diatas, maka peneliti dapat menyajikan pembahasan mengenai temuan yang berhubungan dengan sistem evaluasi pembinaan akhlak di MAN Kota Pariaman sebagai berikut: Berdasarkan temuan data yang telah peneliti uraikan diatas yang terkait dengan fokus penelitian, maka dapat ditemukan sistem evaluasi pembinaan akhlak terhadap Dharma Pramuka di MAN Padusunan Kota Pariaman pada Tahun Pelajaran 2020/2021 dapat dilihat sebagai berikut:

Pertama, Sistem evaluasi yang dilakukan dalam pembinaan akhlak melalui Dharma Pramuka di MAN Padusunan Kota Pariaman adalah dengan melaksanakan perjusmi dengan kegiatan jurit malam dan muhasabah. Kedua, Evaluasi diberikan oleh pelatih, pembina dan kamabigus di MAN Padusunan Kota Pariaman di lapangan dan hall serta posko yang telah dibentuk untuk jurit malam. Ketiga, Pelaksanaan evaluasi pembinaan akhlak melalui Dharma Pramuka di MAN Padusunan Kota Pariaman dilakukan pada malam Jumat dan pada penutupan jurit malam oleh kamabigus. Keempat, Setelah dilakukan evaluasi pembinaan akhlak melalui Dharma Pramuka di MAN Padusunan Kota Pariaman maka terlihat ada perubahan karakter pada peserta didik, baik akhlak terhadap Allah SW'T, akhlak terhadap sesama maupun akhlak kepada lingkungan sekitar.

Kemampuan pelatih, pembina dan kamabigus dalam memberikan evaluasi pembinaan akhlak kepada peserta didik di MAN Kota Pariaman sangat baik sehingga terjadi perubahan karakter pada diri peserta didik kearah yang lebih baik. Setelah peneliti mendapatkan beberapa data yang ditemukan dilapangan, berdasarkan hasil wawancara dengan beberapa orang informan, observasi dan beberapa dokumentasi maka nantinya peneliti akan dapat menganalisis tentang pembinaan akhlak melalui Dharma Pramuka studi fenemologi di MAN Kota Pariaman. Adapun pembinaan akhlak yang dimaksud disini adalah materi yang diberikan kepada peserta didik, metode dalam pembinaan akhlak serta sistem evaluasi yang dilakukan dalam pembinaan akhlak melalui Dharma Pramuka di MAN Kota Pariaman. Dalam hal ini ada dua Dharma yang difokuskan dalam pembinaan akhlak yaitu Dharma takwa kepda tuhan yang maha esa dan Dharma cinta alam dan kasih sayang sesama manusia.

Oleh karena beberapa hal yang peneliti temukan, maka sangat diharapkan adanya pembinaan akhlak terhadap peserta didik melalui Dharma Pramuka. Dewasa ini di MAN Kota Pariaman kegiatan Pramuka digambarkan hanya sebagai kegiatan ekstrakurikuler biasa sehingga tidak ada perbedaan antara anak Pramuka dengann anak yang tidak mengikuti kegiatan Pramuka. Seharusnya anak yang mengikuti kegiatan Pramuka memiliki kepedulian yang tinggi terhadap sesama baik 
dilingkungan keluarga, sekolah dan masyarakat. Adapun program ekstrakurikuler Pramuka di MAN Kota Pariaman diharapkan dapat meningkatkan akhlak peserta didiknya terhadap Allah SWT. Tentunya ini butuh pembinaan baik dari pelatih, pembina, kamabigus serta guru akidah akhlak di sekolah ini. Pembinaan yang diberikan bisa secara langsung maupun secara tidak langsung. Dalam kegiatan observasi penelitian yang peneliti lakukan hal ini sudah terlihat jelas, banyak nilai positif yang dihasilkan dengan adanya pembinaan akhlak yang diberikan oleh pembina, pelatih dan kamabigus melalui Dharma Pramuka di MAN Kota Pariaman.

\section{Penutup}

Adapun materi pembinaan akhlak melalui Dharma Pramuka di MAN Kota Pariaman adalah sebagai berikut 1) Menerapkan Dasa Dharma pramuka sesuai dengan konten pembinaan akhlak yang diinginkan, 2) Dalam pembinaan akhlak melalui Dharma Pramuka di MAN Padusunan Kota Pariaman ada dua metode yang dipakai yaitu metode ceramah dan melalui teladan, penggunaan metode tersebut sesuai dengan kondisi dan materi pembinaan akhlak yang diinginkan, 3) Evaluasi diberikan oleh pelatih, pembina dan kamabigus di MAN Padusunan Kota Pariaman di lapangan dan hall serta posko yang telah dibentuk untuk jurit malam. Pelaksanaan evaluasi pembinaan akhlak melalui Dharma Pramuka di MAN Padusunan Kota Pariaman dilakukan pada malam Jumat dan pada penutupan jurit malam oleh kamabigus.

\section{Referensi}

Aprianto, Aprianto, Mahyudin Ritonga, Yoni Marlius, and Raihan Nusyur. "The Influence of Using Audio- Lingual Method on Students' Speaking Skill in Madrasah Diniyah Takmiliyah Awwaliyyah." Izdihar: Journal of Arabic Language Teaching, Linguistics, and Literature 3, no. 2 (2020): 147-60. https://doi.org/https://doi.org/10.22219/jiz.v3i2.12514.

Boulton-lewis, Gillian M, Joanne M Lunn Brownlee, Sue Walker, C Cobb, and Eva Johansson. "Moral and Social Development: Teachers' Knowledge of Children's Learning and Teaching Strategies in the Early Years." Australasian Journal OfEarly Childhood, no. July 2015 (2011): 1-20.

Elmelki, Anas, and Ben Arab Mounira. "Ethical Investment and the Social Responsibilities of the Islamic Banks." International Business Research 2, no. 2 (2019): 123-30. https://doi.org/10.5539/ibr.v2n2p123.

Fadl, Khaled Abou El. "Qur' anic Ethics and Islamic Law." Journal of Islamic Ethics 1 (2017): 7-28. https://doi.org/10.1163/24685542-12340002.

Haidir, Daisy JP, and Evi Idayani. "Implementation of Moral Values in Scouts (Study on Madrasah Ibtidaiyah State 1 Medan)." Budapest International Research and Critics Institute-Journal (BIRCI-Journal) 3, no. 2 (2020): 1403-12. https://doi.org/https://doi.org/10.33258/birci.v3i2.1000.

Hakim, Rosniati, and Mahyudin Ritonga. "A Study of Religion Education Method

With Multicultural Insight.” In International Seminar on Islamic Education (ISIE 
2018) Faculty of Islamic Religion, Universitas Muhammadiyah Ponorogo, July 07th, 2018, 81-97. Ponorogo: Universitas Muhammadiyah Ponorogo, 2018.

Hakim, Rosniati, Mahyudin Ritonga, Khadijah, and Wetti Susanti. "Implementation of Contextual Teaching and Learning in Islamic Education at Madrasah Diniyah." Journal of Advanced Research in Dynamical \& Control Systems 12, no. 02 (2020): 3326-32. https://doi.org/10.5373/JARDCS/V12I2/S20201455.

Hasbiansyah, O. "Pendekatan Fenomenologi: Pengantar Praktik Penelitian Dalam Ilmu Sosial Dan Komunikasi." MEDIATOR 9, no. 1 (2008): 163-80.

Hutagalung, Ahmad Ichsan Yafi, Humaidah Hasibuan, and Yusnaili Budianti. "Peran Guru Dalam Menanamkan Akhlak Di Kelompok B RA As-Sa'adah Kecamatan Medan Area." Raudhah 06, no. 01 (2018): 1-9. http://jurnaltarbiyah.uinsu.ac.id/index.php/raudhah.

Mills, Sarah. "Scouting for Girls? Gender and the Scout Movement in Britain." Gender, Place \& Culture 18, no. 4 (2011): 537-56. https://doi.org/10.1080/0966369X.2011.583342.

Mislia, Alimuddin Mahmud, and Darman Manda. "The Implementation of Character Education through Scout Activities." International Education Studies 9, no. 6 (2016): 130-38. https://doi.org/10.5539/ies.v9n6p130.

Muhammad. "Pembentukan Karakter Anak SD/MI Melalui Pendidikan Pramuka." Elementary 1, no. 2 (2015): 10-17.

Muhtadi, Ahmad. "Implementation Of National Character Education (Study Of Scouting Activities Analysis At Man 2 Karanganyar)." Attarbiyab: Journal of Islamic Culture and Education 4, no. 1 (2019): 41-68. https://doi.org/10.18326/attarbiyah.v4i1.41-68.

Qomari, Rohmad. "Prinsip Dan Ruang Lingkup Pendidikan Aqidah Akhlaq." INS ANLA: Jurnal Pemikiran Alternatif Kependidikan 14, no. 1 (2009): 1-16.

Ritonga, Mahyudin. "Bargaining Kata Di Dalam Al Qur'an : Kontroversi Ahli Terhadap Bahasa Al Qur'an." Akademika 21, no. 2 (2016): 229-54. http://ejournal.metrouniv.ac.id/index.php/akademika/article/view/466.

. "Desain Bahan Ajar Bahasa Arab Sains Dengan Pendekatan Whole Language." Eduksi: Jurnal Pendidikan Islam 5, no. 1 (2017): 1-24.

Yusuf, Muhammad, Mahyudin Ritonga, and Mursal. "Implementasi Karakter Disiplin Dalam Kurikulum 2013 Pada Bidang Studi PAI Di SMA Islam Terpadu Darul Hikmah.” Jurnal Tarbiyatuna 11, no. 1 (2020): 49-60. https://doi.org/https://doi.org/10.31603/tarbiyatuna.v11i1.3437 Article. 